Check for updates

Cite this: Chem. Commun., 2021, 57,8897

Received 5th June 2021

Accepted 9th August 2021

DOI: $10.1039 / \mathrm{d} 1 \mathrm{cc} 02937 \mathrm{a}$

rsc.li/chemcomm

\section{Aerobic oxidation and oxidative esterification of alcohols through cooperative catalysis under metal-free conditions $\dagger$}

\author{
Babak Karimi, (D) *ab Mina Ghahremani, ${ }^{a}$ Hojatollah Vali, ${ }^{c}$ Rosaria Ciriminna ${ }^{\mathrm{d}}$ and \\ Mario Pagliaro iD *d
}

The ABNOCPMO-IL-Br material obtained by anchoring 9azabicyclo[3.3.1]nonane-3-one $N$-oxyl (keto-ABNO) within the mesopores of periodic mesoporous organosilica with bridged imidazolium groups is a robust bifunctional catalyst for the metal-free aerobic oxidation of numerous primary and secondary alcohols under oxygen balloon reaction conditions. The catalyst, furthermore, can be successfully employed in the first metal-free selfesterification of primary aliphatic alcohols affording valued esters.

Thanks to their high selectivity and pronounced versatility, stable nitroxyl radicals of the TEMPO (2,2,6,6-tetramethylpiperidine-1-oxyl) family are now well established as environmentally benign catalysts for the selective oxidation of a wide variety of alcohols to carbonyl compounds (and to carboxylic acids when reaction is carried out in water). ${ }^{1}$ Primary oxidants such as bleach (NaOCl), hypervalent iodine reagents, and $\mathrm{O}_{2}$ in combination with $\mathrm{NO}_{x}$ co-catalysts such as tert-butylnitrite $(\mathrm{TBN})^{2}$ and sodium nitrite ${ }^{3}$ are generally employed to promote catalytic turnover. Since the first transitionmetal-free TEMPO-catalyzed aerobic oxidation of alcohols using molecular oxygen as a terminal oxidant, the catalytic method has replaced most alcohol oxidation stoichiometric routes, especially those based on highly toxic chromium(vi) reagents and other metal oxidants that until a decade ago were still widely employed to oxidise alcohols in the fine chemical and pharmaceutical industries. ${ }^{4}$

Sterically hindered by the four methyl groups, the oxoammonium group of TEMPO ensures the chemoselective

\footnotetext{
${ }^{a}$ Faculty of Chemistry, Institute for Advanced Studies in Basic Sciences (IASBS), Gava Zang, PO Box 45195-1159, Zanjan 45137-66731, Iran. E-mail: karimi@iasbs.ac.ir

${ }^{b}$ Research Center for Basic Sciences \& Modern Technologies (RBST), Institute for Advanced Studies in Basic Sciences (IASBS), Zanjan 45137-66731, Iran ${ }^{c}$ Department of Anatomy and Cell Biology and Facility for Electron Microscopy Research McGill University, Montreal, Quebec, H3A 2A7, Canada

${ }^{d}$ Istituto per lo Studio dei Materiali Nanostrutturati, CNR via U. La Malfa 153, Palermo 90146, Italy.E-mail: mario.pagliaro@cnr.it

$\dagger$ Electronic supplementary information (ESI) available. See DOI: 10.1039/d1cc02937a
}

oxidation of primary alcohols in the presence of unprotected secondary alcohol groups, but the applicability of TEMPObased catalysts in the oxidation of non-activated aliphatic, secondary and sterically hindered primary alcohols is often limited by the same steric constraints. ${ }^{5}$ To expand the scope of nitroxyl radical mediated-oxidations, the use of less hindered bicyclic nitroxyl radicals such as 2-azaadamantan- $N$-oxyl (AZADO) and 9-azabicyclo[3.3.1]nonane- $\mathrm{N}$-oxyl (ABNO) has become increasingly common. ${ }^{6}$

Obtained through a multi-step (i.e. up to four steps to synthesis 1-Me-AZADO) synthetic process, ${ }^{7}$ AZADO derivatives are relatively difficult to access. Prepared through a three-step synthetic route, the radical ABNO is an economically viable nitroxyl radical bearing hydrogen atoms on the $\alpha$-carbons (avoiding to violate Bredt's rule) alternative to AZADO. ${ }^{8}$ Known since the mid-1960s, ${ }^{9}$ such less-hindered nitroxyl radicals mediate the oxidation of sterically hindered alcohols for which TEMPO is not a suitable catalyst. Applications include the efficient oxidation of chiral alcohols using chirally modified AZADOs ${ }^{10}$ as well as 9-azanoradamantane $N$-oxyl (Nor-AZADO) exhibiting higher catalytic activity than AZADO, ABNO and TEMPO. ${ }^{11}$ Furthermore, combined with $\mathrm{HNO}_{3}, \mathrm{NaNO}_{2}$ (or both) as co-catalysts and $\mathrm{O}_{2}$ as primary oxidant, $\mathrm{ABNO}$ and 9-azabicyclo[3.3.1]nonane-3-one $\mathrm{N}$-oxyl (keto-ABNO) effectively mediate the oxidation of secondary alcohols along with imines bearing diverse functional groups. ${ }^{12}$ Similarly, in combination with a catalytic amount of $\mathrm{Cu}(\mathrm{I})$, keto-ABNO successfully catalyzes the selective oxidation of secondary alcohols, including unactivated aliphatic substrates. ${ }^{13}$ The first metal- and halogen-free keto-ABNO catalyst for the aerobic oxidation of alcohols under mild reaction conditions was reported in 2014. ${ }^{14 a}$ Denoted as SABNO, the latter is an heterogeneous catalytic system comprised of SBA-15 functionalized with ketoABNO showing superior catalytic activity over SBA-15-supported TEMPO in the aerobic oxidation of a wide range of alcohols bearing diverse functional groups under conditions similar to those used with homogenous catalysts. ${ }^{14 b}$ We now report a 

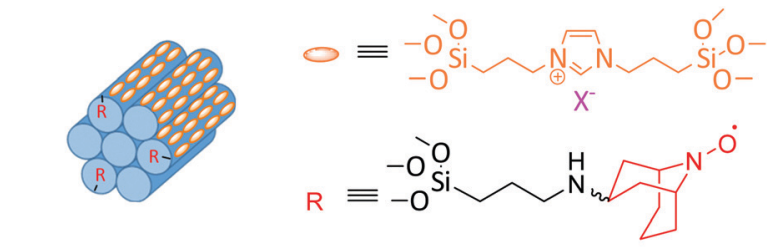

ABNO@PMO-IL-X

$\mathrm{X}=\mathrm{Br}^{-}$or $\mathrm{Cl}^{-}$

Fig. 1 Schematic representation of ABNO@PMO-IL; for details of the preparation, see ESI. $\dagger$

newly supported ABNO heterogeneous catalyst using a periodic mesoporous silica functionalized with an imidazolium framework (PMO-IL) as support in the metal-free aerobic oxidation of alcohols, in analogy to the catalyst system comprising a robust PMO with bridged imidazolium network (PMO-IL) further functionalized with TEMPO (Fig. 1). ${ }^{15}$

The new catalyst, ABNO@PMO-IL, displays enhanced catalytic activity in comparison to the latter PMO-IL system as well to IL-free analogues due to the imidazolium bromide units in close proximity to the ABNO moieties. A robust PMO with bridged imidazolium network (PMO-IL) was initially prepared according to previously reported protocol, wherein 1,3-bis (3-trimethoxysilylpropyl)imidazolium chloride and $\mathrm{Si}(\mathrm{OMe})_{4}$ are hydrolyzed and co-condensed in the presence of Pluronic P123 as a template under acidic conditions. ${ }^{16}$ The ABNO radical was then anchored to the inner mesoporous network by mixing ABNO-functionalized silane, obtained via reductive amination of keto-ABNO with 3-(amino propyl) trimethoxysilane in the presence of $\mathrm{NaBH}_{3} \mathrm{CN}$. The textural properties of the resulting ABNO@PMO-IL-Cl catalyst and PMO-IL are shown in Table 1 and Fig. 2a (wherein for clarity isotherms are shifted along the $y$-axis) illustrate.

The type IV $\mathrm{N}_{2}$ adsorption-desorption isotherms with sharp hysteresis loop (Fig. 2a) are characteristic of highly ordered mesoporous materials with a regular array of 2D hexagonal pore structure. The specific surface area, total pore volume and pore diameter of ABNO@PMO-IL-Cl lower than those of pristine PMO-IL, indicate that the organic moieties are grafted in the inner surface of the mesochannels. This outcome is further supported by TEM images of ABNO@PMO-IL, showing highly ordered cylindrical pores of uniform size (Fig. 2b). The X-ray photoelectron spectroscopy (XPS) survey of ABNO@PMO-IL-Cl (Fig. 3) confirms the presence of $\mathrm{C}, \mathrm{Si}, \mathrm{O}, \mathrm{Cl}$ and $\mathrm{N}$ as the only elements comprising this material, with chlorine present in the form of chloride ions balancing the positive charge of the IL framework. A closer look at the photoemission spectrum of the $\mathrm{N}$ (1s) line reveals (inset in Fig. 3) two main contributions at $399.26 \mathrm{eV}$ (with a full width at half maximum, FWHM, of 1.48 $\mathrm{eV})$ and $401.17 \mathrm{eV}(\mathrm{FWHM}=2.02)$ binding energy, respectively.

Table 1 Textural properties of PMO-IL and ABNO@PMO-IL-Cl

\begin{tabular}{llll}
\hline Material & $S_{\text {BET }}\left(\mathrm{m}^{2} \mathrm{~g}^{-1}\right)$ & $r_{\mathrm{P}}(\mathrm{nm})$ & $V_{\mathrm{P}}\left(\mathrm{cm}^{3} \mathrm{~g}^{-1}\right)$ \\
\hline PMO-IL & 526.65 & 5.29 & 1.002 \\
ABNO@PMO-IL & 231.10 & 3.53 & 0.43
\end{tabular}
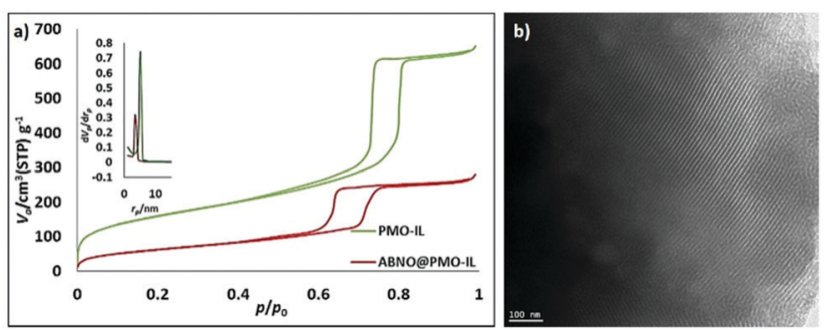

Fig. 2 (a) $\mathrm{N}_{2}$ adsorption-desorption isotherms of all materials including PMO-IL and ABNO@PMO-IL-Cl and inset BJH pore size distribution. $V_{a}$ refers to the volume of adsorbed nitrogen in the pores of the materials. (b) Side view TEM images of ABNO@PMO-IL-Cl. (Scale bar: $100 \mathrm{~nm}$ ).

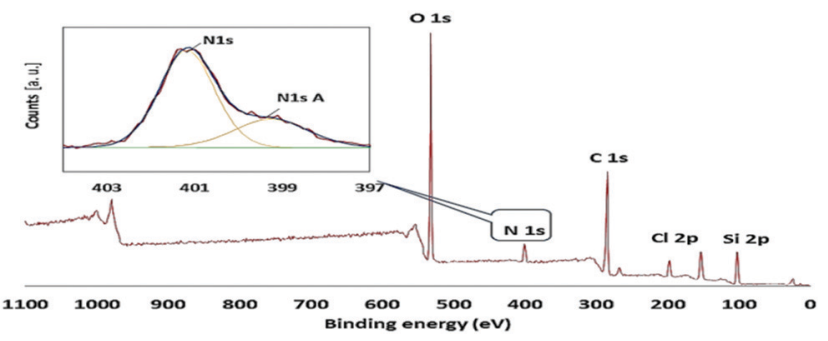

Fig. 3 XPS survey spectrum of ABNO@PMO-IL, and (inset) XPS spectrum of the $\mathrm{N}$ (1s) electrons of ABNOAPMO-IL.

According to literature data, ${ }^{17}$ the peak at 401.17 is attributed to two nitrogen atoms in the imidazolium ring, whereas the first signal at 399.26 is attributed to the nitrogen of the nitroxide group NO, ${ }^{18}$ part of the ABNO molecular moieties attached to the surface of PMO-IL through the $\mathrm{C}-\mathrm{N}$ covalent bond. This finding is further corroborated by the results of the thermogravimetric analysis (TGA) pointing to a loading of ABNO and IL groups at 0.26 and $0.97 \mathrm{mmol} \mathrm{g}^{-1}$, respectively (ESI, $\dagger$ Fig. S1).

Evidence of successful anchoring of ABNO on the inner surface of PMO-IL was further obtained by Fourier-transform infrared spectroscopy (FT-IR). Besides the signals characteristic of alkylimidazolium groups, the FTIR spectrum of ABNO@PMO-IL-Cl displays a new band at $1351 \mathrm{~cm}^{-1}$ related to the $\mathrm{N}-\mathrm{O}$ free radicals (Fig. S2, ESI $\dagger$ ) in good agreement with previous results concerning PMO-IL functionalized with TEMPO. ${ }^{15}$

Tested in the aerobic oxidation of benzyl alcohol $(\mathrm{BnOH})$ as a model substrate under relatively mild conditions with TBN as nitrite source $(1 \mathrm{~mol} \%$ catalyst, $0.5 \mathrm{~mL}$ toluene, $10 \mathrm{~mol} \% \mathrm{HCl}$, $8 \mathrm{~mol} \% \mathrm{TBN})$ at $50{ }^{\circ} \mathrm{C}$, the ABNO@PMO-IL-Cl showed more activity than SABNO (Table 2, entries 1 and 2). Therefore, we decided to replace the chloride counter ions with bromide ions by stirring the ABNO@PMO-IL-Cl catalyst in a saturated solution of $\mathrm{NaBr}$ for $24 \mathrm{~h}$. To our delight, employed in the aerobic oxidation of $\mathrm{BnOH}$ under the aforementioned conditions, the new ABNO@PMO-IL-Br catalyst exhibited excellent catalytic activity not only in comparison to ABNO@PMO-IL-Cl but also to IL-free SABNO, PMO-IL functionalized with TEMPO, and even to homogeneous keto-ABNO (Table 2). The use PMO-IL as a catalyst (Table 2; entry 6) resulted only in $15 \%$ yields of benzaldehyde even after $12 \mathrm{~h}$, clearly showing the 
Table 2 Screening of aerobic oxidation of benzyl alcohol using ABNO functionalized PMO-IL and SBA-15 catalysts

\begin{tabular}{llll}
\hline Entry & Material & $t(\mathrm{~min})$ & Conv. (\%) \\
\hline 1 & ABNO@PMO-IL-Cl & 120 & $97^{a}$ \\
2 & ABNO@SBA-15 (SABNO) & 120 & $90^{a}$ \\
3 & ABNO@PMO-IL-Br & $\mathbf{3 0}$ & $>\mathbf{9 9}^{a}$ \\
4 & TEMPO@PMO-IL-Br & 120 & 98 \\
5 & Keto-ABNO & 30 & $90^{b}$ \\
6 & PMO-IL & $12 \mathrm{~h}$ & $15^{c}$
\end{tabular}

${ }^{a}$ Conditions: catalyst $(1 \mathrm{~mol} \%)$ in the presence of $\mathrm{O}_{2}$ (oxygen balloon, $621-622$ torr) $\mathrm{HCl}(10 \mathrm{~mol} \%)$ as additive and $t$-BuONO (TBN, $8 \mathrm{~mol} \%)$ in toluene $(0.5 \mathrm{~mL})$ as a solvent in the presence of molecular oxygen. ${ }^{b}$ Using homogeneous Keto-ABNO $(1 \mathrm{~mol} \%) .{ }^{c}$ Using PMO-IL at the corresponding IL loading $(10 \%)(40 \mathrm{mg})$ prolonged time to $12 \mathrm{~h}$. All yields obtained via GC analysis using a standard method.

crucial importance of co-supported $\mathrm{ABNO}$ and imidazolium bromide in obtaining high catalytic activity. We thus tested the new catalyst and the catalytic protocol in the selective oxidation of different alcohol substrates. Results in Table 3 show that good to excellent yields were obtained in relatively short time with all substrates.

Even deactivated 2-nitrobenzyl alcohol was converted into the corresponding 2-nitrobenzaldehyde (an important precursor of indigo carmine) in $67 \%$ yield (entry 14 in Table 3 ). The oxidation of sterically hindered $\alpha$-tetralol smoothly proceeded, affording in $4 \mathrm{~h}$ a $96 \%$ yield in 1-tetralone (entry 24). For comparison, the state-of-the art oxidation at room temperature of the same substrate affording $89 \%$ yield in 1-tetralone mediated by $\left(\mathrm{Ph}_{4} \mathrm{P}\right)\left[\mathrm{RuO}_{2} \mathrm{Cl}_{3}\right]$ dissolved in dichloromethane requires a three-fold excess of $N$-methylmorpholine- $N$-oxide (NMO) a primary oxidant in the presence of $4 \AA$ molecular sieves. ${ }^{19}$ The lowest yield in selectively oxidised product was recorded for cyclooctanol affording $63 \%$ yield in cyclooctanone (entry 29). For comparison, the oxidative dehydrogenation of cyclooctanol to cyclooctanone over $\mathrm{Pd} / \mathrm{MgO}$ under $\mathrm{O}_{2}$ at $70-80{ }^{\circ} \mathrm{C}$ affords a $58 \%$ yield. ${ }^{20}$ Not involving catalytic metal species, the ABNO@PMO-IL-Br catalyst is ideally suited for the conversion of sulfur-containing substrates such as 4-(methylthio)benzyl alcohol which is quickly converted into 4 -(methylthio) benzaldehyde in $98 \%$ yield (entry 17 ). The aldehyde is the valued raw material of nonsteroidal antiinflammatory drug "sulindac". For comparison the best current catalyst using air as primary oxidant, $\mathrm{MnCo}_{2} \mathrm{O}_{4}$, catalyzes the selective oxidation of 4 -(methylthio)benzyl alcohol to the 4-(methylthio) benzaldehyde in $96.5 \%$ yield. ${ }^{21}$ Finally, it is remarkable how the new catalyst successfully mediates the oxidation of secondary alcohols (entries 19-23 and 25-27) affording excellent ( $>95 \%$ ) yields under the same conditions employed for converting primary and secondary alcohols to aldehydes and to ketones, respectively. The latter alcohols are generally considered to be unaffected under the conditions employed for the conversion of primary and secondary alcohol substrates. $^{22}$ The suitability of the catalysis for acid-sensitive silyl ether and acetal groups remains to be investigated.

The direct oxidative esterification of alcohols to esters over metal catalysts such as $\mathrm{Ru},{ }^{23} \mathrm{Pd},{ }^{24} \mathrm{Ir},{ }^{25} \mathrm{Au},{ }^{26} \mathrm{Co}\left(\text { and } \mathrm{Co}_{3} \mathrm{O}_{4}\right)^{27}$
Table 3 Aerobic oxidation of various alcohols using ABNO@PMO-IL-Br catalyst under metal-free conditions

\begin{tabular}{|c|c|c|c|c|}
\hline & & & 0.5 & $>99$ \\
\hline & 4-Me- $-\mathrm{C}_{6} \mathrm{H}_{5}$ & $\mathrm{H}$ & 0.5 & $>99$ \\
\hline & $3-\mathrm{Me}-\mathrm{C}_{6} \mathrm{H}_{5}$ & $\mathrm{H}$ & 0.5 & $>99$ \\
\hline & $2-\mathrm{Me}-\mathrm{C}_{6} \mathrm{H}_{5}$ & $\mathrm{H}$ & 0.66 & $>99$ \\
\hline & 4-iPr- $\mathrm{C}_{6} \mathrm{H}_{5}$ & $\mathrm{H}$ & 0.66 & $>99$ \\
\hline & $4-\mathrm{Cl}-\mathrm{C}_{6} \mathrm{H}_{5}$ & $\mathrm{H}$ & 1 & $>99$ \\
\hline & $3-\mathrm{Cl}-\mathrm{C}_{6} \mathrm{H}_{5}$ & $\mathrm{H}$ & 1 & 97 \\
\hline & $2-\mathrm{Cl}-\mathrm{C}_{6} \mathrm{H}_{5}$ & $\mathrm{H}$ & 1.25 & 97 \\
\hline & $4-\mathrm{Br}-\mathrm{C}_{6} \mathrm{H}_{5}$ & $\mathrm{H}$ & 1 & $>98$ \\
\hline 10 & $2-\mathrm{Br}-\mathrm{C}_{6} \mathrm{H}_{5}$ & $\mathrm{H}$ & 1.5 & 95 \\
\hline 11 & 2,4-DiCl- $\mathrm{C}_{6} \mathrm{H}_{5}$ & $\mathrm{H}$ & 2 & 87 \\
\hline 2 & $4-\mathrm{NO}_{2}-\mathrm{C}_{6} \mathrm{H}_{5}$ & $\mathrm{H}$ & 1.5 & 94 \\
\hline 13 & $3-\mathrm{NO}_{2}-\mathrm{C}_{6} \mathrm{H}_{5}$ & $\mathrm{H}$ & 2 & 86 \\
\hline 14 & $2-\mathrm{NO}_{2}-\mathrm{C}_{6} \mathrm{H}_{5}$ & $\mathrm{H}$ & 5 & 67 \\
\hline 15 & $4-\mathrm{MeO}-\mathrm{C}_{6} \mathrm{H}_{5}$ & $\mathrm{H}$ & 1.5 & 94 \\
\hline 16 & $2-\mathrm{MeO}-\mathrm{C}_{6} \mathrm{H}_{5}$ & $\mathrm{H}$ & 2 & 95 \\
\hline 17 & $4-\mathrm{MeS}-\mathrm{C}_{6} \mathrm{H}_{5}$ & $\mathrm{H}$ & 1.5 & 95 \\
\hline 18 & 1-Naphtyl & $\mathrm{H}$ & 1 & $>98$ \\
\hline 19 & $\mathrm{C}_{6} \mathrm{H}_{5}$ & $\mathrm{Me}$ & 1 & $98^{b}$ \\
\hline 20 & $4-\mathrm{Ph}-\mathrm{C}_{6} \mathrm{H}_{5}$ & $\mathrm{Me}$ & 12 & $>99^{b}$ \\
\hline 21 & $\mathrm{C}_{6} \mathrm{H}_{5}$ & Et & 1 & $97^{b}$ \\
\hline 22 & $\mathrm{C}_{6} \mathrm{H}_{5}$ & $\mathrm{Ph}$ & 4 & $96^{b}$ \\
\hline 3 & $\mathrm{C}_{6} \mathrm{H}_{5}$ & Cyclopentyl & 3 & $95^{b}$ \\
\hline 4 & $\alpha$-Tetralol & - & 4 & $97^{b}$ \\
\hline 5 & $\mathrm{CH}_{3}\left(\mathrm{CH}_{2}\right)_{4}$ & $\mathrm{Me}$ & 7 & $92^{c}$ \\
\hline 26 & $\mathrm{CH}_{3}\left(\mathrm{CH}_{2}\right)_{5}$ & $\mathrm{Me}$ & 7 & $90^{c}$ \\
\hline 77 & Cyclohexyl & $\mathrm{Me}$ & 8 & $95^{c}$ \\
\hline 8 & Cycloheptyl & - & 9 & $99^{c}$ \\
\hline 99 & Cyclooctyl & - & 10 & $63^{c}$ \\
\hline 30 & Norbornyl & - & 10 & $86^{c}$ \\
\hline 31 & 2-Admantyl & - & 8 & $>99^{c}$ \\
\hline 2 & $\mathrm{C}_{6} \mathrm{H}_{5}$ & $\mathrm{H}$ & 12 & \\
\hline
\end{tabular}

Conditions. ${ }^{a}$ Catalyst $(1 \mathrm{~mol} \%)$ in the presence of $\mathrm{O}_{2}$ (oxygen balloon, 621-622 torr), $10 \mathrm{~mol} \% \mathrm{HCl}, 8 \mathrm{~mol} \%$ TBN, $0.3 \mathrm{~mL}$ toluene. ${ }^{b} 5 \mathrm{~mol} \%$ HCl. ${ }^{c} 1.5-2 \mathrm{~mol} \%$ catalyst, $16 \mathrm{~mol} \% \mathrm{TBN}, 5 \mathrm{~mol} \% \mathrm{HCl}, 0.3 \mathrm{~mL}$ toluene. ${ }^{d}$ Catalyst-free conditions. All yields obtained via GC analysis using an internal standard FID calibration method (Fig. S4-S33).

has been widely investigated as an important and highly atomeconomic process. Although being a highly desirable process for the industrial production of esters, the environmental and economic concerns associated with the high temperature and pressure involved in state-of-the-art catalytic processes using precious metal catalysts are important issues that remain to be addressed. ${ }^{28}$ We thus investigated the activity of ABNO@PMOIL-Br in the direct oxidative esterification of alcohols, carrying out the aerobic oxidation of $\mathrm{BnOH}$ under the optimized conditions of entry 1 in Table 3. Prolonging the reaction time to $24 \mathrm{~h}$ showed no self-esterification product. Similarly, increasing the amount of catalyst to $2 \mathrm{~mol} \%$ and using $16 \mathrm{~mol} \%$ of TBN nitrite source and $5 \mathrm{~mol} \%$ of $\mathrm{HCl}$, did not lead to the formation of benzyl benzoate. However, using the new catalyst in the aerobic oxidation of primary aliphatic alcohols efficiently affords selfesterified products (Table 4). To the best of our knowledge, this is the first report on the self-esterification of primary aliphatic alcohols using a nitroxyl radical catalyst system under metalfree conditions (for proposed mechanism of self-esterification 
Table 4 Self-esterification of primary aliphatic alcohols over ABNO@ $\mathrm{PMO}-\mathrm{IL}-\mathrm{Br}$ under metal-free conditions

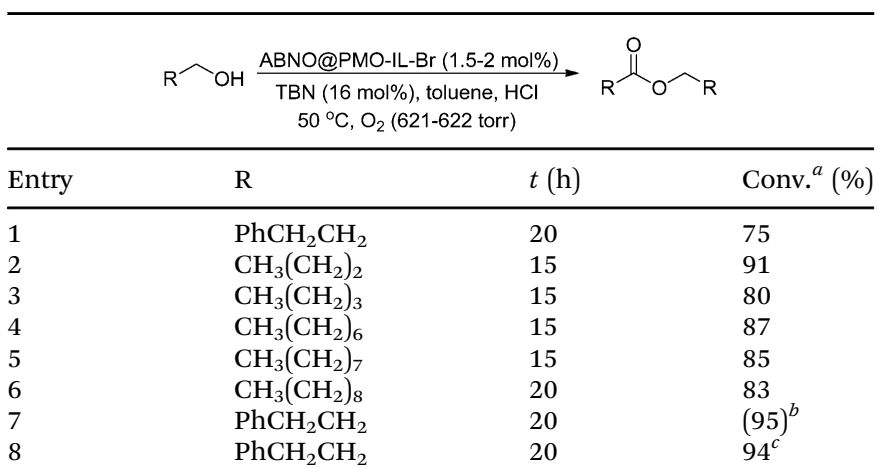

Conditions. ${ }^{a} 1.5-2 \mathrm{~mol} \%$ of catalyst in the presence of molecular oxygen, $5 \mathrm{~mol} \% \mathrm{HCl}$ as an additive and $16 \mathrm{~mol} \%$ TBN in $0.3 \mathrm{~mL}$ toluene as a solvent. All products were detected using NMR spectroscopy. The progress of the reactions was monitored by GC. ${ }^{b}$ Using Keto-ABNO ( $2 \mathrm{~mol} \%$ ), yields in parenthesis refer to the corresponding aldehyde. ${ }^{c}$ Using SABNO ( $2 \mathrm{~mol} \%$ ), yield refer to the corresponding aldehyde.

see Scheme $\mathrm{S} 1$ in the ESI $\dagger$ ). Attempts to synthesis self-esterification products either using homogenous keto-ABNO or SABNO under optimized conditions were unsuccessful (aldehydes are the sole products). This result highlights the importance of near molecular proximity of supported $\mathrm{ABNO}$ and imidazolium bromide in the nanoscale cavities of ABNO@PMO-IL-Br that could synergistically contribute to the unique selective oxidative self-esterification of primary aliphatic alcohols.

In summary, we have discovered that anchoring of ABNO moieties within the nanochannels of a PMO functionalized with imidazolium bromide network affords a catalyst showing enhanced catalytic activity in the metal-free aerobic oxidation of numerous primary benzylic and secondary alcohols. Activity is much higher than that of IL-free SABNO and PMO-IL functionalized with TEMPO excellent catalysts, and even slightly higher than homogenous keto-ABNO. The same ABNO@PMO-IL-Br solid catalyst allows to perform the one-pot oxidative esterification of non-activated aliphatic alcohols under mild reaction conditions. The catalyst could be recycled in three consecutive reactions run in the oxidation of benzyl alcohol with only a slight decrease in catalytic activity. Besides a few interesting metal-free protocols for aerobic oxidation of alcohols,$^{28}$ these results open the route to new effective and versatile approach for carrying out alcohol selective oxidations and selective oxidative self-esterification of primary aliphatic alcohols under mild metal-free conditions (oxygen balloon, $50{ }^{\circ} \mathrm{C}$ ).

The authors acknowledge IASBS Research Councils, and Iranian National Science Foundation (INSF) to grant the research (No. 99022450), the Alexander von Humboldt Foundation (B. K.), NanoQuebec and NSER Council of Canada (H. V.) for support of this work.

\section{Conflicts of interest}

The authors have no conflicts of interest to declare.

\section{Notes and references}

1 R. A. Sheldon, Catal. Today, 2015, 247, 4.

2 (a) Y. Xie, W. M. Mo, D. Xu, Z. L. Shen, N. Sun, B. X. Hu and X. Q. Hu, J. Org. Chem., 2007, 72, 4288; (b) X. He, Z. Shen, W. Mo, N. Sun, B. Hu and X. Hu, Adv. Synth. Catal., 2009, 351, 89; (c) C. Qiu, L. Jin, Z. Huang, Z. Tang, A. Lei, Z. Shen, N. Sun, W. Mo, B. Hu and X. Hu, ChemCatChem, 2012, 4, 76.

3 (a) X. Wang, R. Liu, Y. Jin and X. Liang, Chem. - Eur. J., 2008, 14, 2679; (b) C.-X. Miao, L.-N. He, J. Wang and J. Wang, Adv. Synth. Catal., 2009, 351, 2209; (c) C.-X. Miao, L.-N. He, J. Wang and F. Wu, J. Org. Chem., 2010, 75, 257.

4 (a) R. H. Liu, X. M. Liang, C. Y. X. Dong and Q. Hu, J. Am. Chem. Soc., 2004, 126, 4112; (b) R. Ciriminna and M. Pagliaro, Org. Process Res. Dev., 2010, 14, 245.

5 H. A. Beejapur, Q. Zhang, K. Hu, L. Zhu, J. Wang and Z. Ye, ACS Catal., 2019, 9(4), 2777.

6 S. Wertz and A. Studer, Green Chem., 2013, 15, 3116.

7 (a) M. Shibuya, Y. Osada, Y. Sasano, M. Tomizawa and Y. Iwabuchi, J. Am. Chem. Soc., 2011, 133, 6497; (b) M. Shibuya, Y. Sasano, M. Tomizawa, T. Hamada, M. Kozawa, N. Nagahama and Y. Iwabuchi, Synthesis, 2011, 3418-3425.

8 M. Shibuya, M. Tomizawa, Y. Sasano and Y. Iwabuchi, J. Org. Chem., 2009, 74, 4619.

9 R. M. Dupeyre and A. Rassat, J. Am. Chem. Soc., 1966, 88, 3180.

10 M. Tomizawa, M. Shibuya and Y. Iwabuchi, Org. Lett., 2009, 11, 1829.

11 (a) M. Hayashi, Y. Sasano, S. Nagasawa, M. Shibuya and Y. Iwabuchi, Chem. Pharm. Bull., 2011, 59, 1570; (b) H. Inada, K. Furukawa, M. Shibuya and Y. Yamamoto, Chem. Commun., 2019, 55, 15105.

12 (a) M. B. Lauber and S. S. Stahl, ACS Catal., 2013, 3, 2612; (b) T. Sonobe, K. Oisaki and M. Kanai, Chem. Sci., 2012, 3, 3249.

13 L. Rogan, N. L. Hughes, Q. Cao, L. M. Dornan and M. J. Muldoon, Catal. Sci. Technol., 2014, 4, 1720.

14 (a) B. Karimi, E. Farhangi, H. Vali and S. Vahdati, ChemSusChem, 2014, 7, 2735; (b) B. Karimi, A. Biglari, J. H. Clark and V. Budarin, Angew. Chem., Int. Ed., 2007, 46, 7210.

15 B. Karimi, S. Vahdati and H. Vali, RSC Adv., 2016, 6, 63717.

16 B. Karimi, D. Elhamifar, J. H. Clark and A. J. Hunt, Chem. - Eur. J., 2010, 16, 8047.

17 (a) J. Tan, D. Fang, Y. Liu and L. Hu, New J. Chem., 2019, 43, 2583; (b) H. P. Steinruck, Phys. Chem. Chem. Phys., 2012, 14, 5010.

18 (a) O. Swiech, R. Bilewicz and E. Megiel, RSC Adv., 2013, 3, 5979; (b) A. C. Dengel, W. P. Griffith, A. M. El-Hendawy and J. M. Jolliffe, Polyhedron, 1990, 9, 1751-1756.

19 U. R. Pillai and E. Sahle-Demessie, Green Chem., 2004, 6, 161.

20 D. Li, F. Ruan, Y. Jin, Q. Ke, Y. Cao, H. Wang, T. Wang, Y. Song and P. Cui, Catal. Sci. Technol., 2019, 9, 418.

21 D. Chen, Y. Zhang, X. Pan, F. Wang and S. Huang, Adv. Synth. Catal., 2018, 360, 3607.

22 (a) J. Zhang, G. Leitus, Y. Ben-David and D. Milstein, J. Am. Chem. Soc., 2005, 127, 10840; (b) C. Gunanathan, L. J. W. Shimon and D. Milstein, J. Am. Chem. Soc., 2009, 131, 3146; (c) M. Nielsen, H. Junge, A. Kammer and M. Beller, Angew. Chem., Int. Ed., 2012, 51, 5711.

23 (a) S. Gowrisankar, H. Neumann and M. Beller, Angew. Chem., Int. Ed., 2011, 50, 5139; (b) C. Liu, J. Wang, L. Meng, Y. Deng, Y. Li and A. Lei, Angew. Chem., Int. Ed., 2011, 22, 5144.

24 N. Yamamoto, Y. Obora and Y. Ishii, J. Org. Chem., 2011, 76, 2937.

25 H. Miyamura, T. Yasukawa and S. Kobayashi, Green Chem., 2010, $12,776$.

26 (a) R. V. Jagadeesh, H. Junge, M.-M. Pohl, J. Radnik, A. Brückner and M. Beller, J. Am. Chem. Soc., 2013, 135, 10776; (b) W. Zhong, H. Liu, C. Bai, S. Liao and Y. Li, ACS Catal., 2015, 5, 1850.

27 J. Otera and J. Nishikido, Esterification: Methods, Reactions, and Applications, John Wiley \& Sons, New York, 2nd edn, 2010.

28 (a) Z. Wang, J. Shi, D. Wang, Y. Pu, J. X. Wang and J. F. Chen, React. Chem. Eng., 2019, 4, 507-515; (b) A. Das and S. S. Stahl, Angew. Chem., Int. Ed., 2017, 56, 8892-8897; (c) W. Schilling, D. Riemer, Y. Zhang, N. Hatami and S. Das, ACS Catal., 2018, 8(6), 5425-5430; (d) S. Abednatanzi, P. G. Derakhshandeh, K. Leus, H. Vrielinck, F. Callens, J. Schmidt, A. Savateev and P. Van Der Voort, Sci. Adv., 2020,6 , eaaz2310. 